\title{
Breast Cancer and Its Screening Awareness in the North Region of Cameroon
}

\section{Erika Myriam Baiguerel ${ }^{1}$, Richard Simo Tagne ${ }^{*}\left(\mathbb{D}\right.$, Armel Hervé Kamdje Nwabo²$^{2}$, Charlette Nangue ${ }^{3}$, Ahmadou Mohamadou1, Paul Faustin Seke Etet ${ }^{2}$, Phelix Bruno Telefo ${ }^{4}$}

${ }^{1}$ Department of Biomedical Sciences, Faculty of Science, University of Ngaoundere, Ngaoundere, Cameroon

${ }^{2}$ Department of Physiological Sciences and Biochemistry, Faculty of Medicine and Biomedical Sciences, University of Ngaoundere, Garoua, Cameroon

${ }^{3}$ Anatomo-Cytopathology Laboratory, University Hospital Center of Yaounde, Yaounde, Cameroon

${ }^{4}$ Department of Biochemistry University of Dschang, Dschang, Cameroon

Email: *rstagne@gmail.com

How to cite this paper: Baiguerel, E.M., Tagne, R.S., Nwabo, A.H.K., Nangue, C., Mohamadou, A., Etet, P.F.S. and Telefo, P.B. (2021) Breast Cancer and Its Screening Awareness in the North Region of Cameroon. Journal of Cancer Therapy, 12, 424-436. https://doi.org/10.4236/jct.2021.127037

Received: June 12, 2021

Accepted: July 13, 2021

Published: July 16, 2021

Copyright $\odot 2021$ by author(s) and Scientific Research Publishing Inc. This work is licensed under the Creative Commons Attribution International License (CC BY 4.0).

http://creativecommons.org/licenses/by/4.0/

\section{Abstract}

Due to the late diagnosis, resulting partly from the absence of national screening programs, breast cancer has become a real public health problem in $\mathrm{Ca}$ meroon, particularly in rural areas. This work aimed to assess breast cancer awareness in the North Region of Cameroon. Participants were selected randomly in six health centers surrounding rural areas of Garoua, North Region of Cameroon, and administered a questionnaire aimed at assessing their awareness about breast cancer warning signs and screening methods. Out of 475 women (including 37 medical personnel) interviewed, $23.3 \%$ had misconceptions and myth-based ideas on the origin of the disease. Employed women were more aware of breast cancer, its risk factors and symptoms as compared to other groups ( $\mathrm{p}<0.0001)$ for most of the risk factors and symptoms. Participants with higher education and employed women were also more aware of breast cancer screening, including breast self-examination mammography, and breast ultrasound ( $\mathrm{p}<0.0001$ vs. other groups). Breast cancer screening and breast self-examination were mostly performed by women with higher education and employed women ( $\mathrm{p}<0.0001$ compared to other groups). Ignorance was the main reason preventing women from performing breast self-examination and the high cost prevented going for mammography. Our study highlights the need to raise awareness among the populations in Cameroon North Region about the risk factors and clinical signs of breast cancer and the importance of screening practice for the early diagnosis of breast cancer.
\end{abstract}




\section{Keywords}

Breast Cancer, Awareness, Screening, North Region of Cameroon

\section{Introduction}

Breast cancer is the second most common cancer in the world and the deadliest cancer in women worldwide by far, it has become a real public health concern and challenge as it is the leading cause of cancer-related deaths amongst women, particularly in developing countries where the situation is seriously increasing [1] [2]. About 2.1 million women were diagnosed with breast cancer in 2018, and 626,679 breast cancer-related deaths were reported. These represented increases of $19 \%$ in the incidence and $17 \%$ in the mortality rates as compared to 2012 [1] [3] [4] [5]. In Africa, breast cancer represented 16\% of cancer incidence and $18.3 \%$ of cancer-related mortality in 2018. In Cameroon, the situation is becoming alarming as breast cancer-related mortality rate displayed an increase of 34\% between 2012 and 2018. 3273 new cases were diagnosed and 1780 women died of breast cancer in 2018, ranking the cancer with the highest incidence and highest death toll in Cameroon [1] [6]. Also alarming, the number of women younger than 35 diagnosed with severe high-grade breast cancer has been increasing [7] [8] [9]. The five-year median survival rate is $22 \%$, and most patients die within 12 months after diagnosis [10] [11] [12] [13].

Early detection of breast cancer in asymptomatic women through screening is aimed at detecting the disease when it is less invasive, reducing advanced stage-associated morbidity and its rate of mortality [14] [15]. Tools like the widely recognized Breast Cancer Risk Assessment Tool (BCRAT or Gail model) that were developed and adapted for the disparity in racial and ethnic groups in developed countries, in particular in the United States, has been proving challenging to adapt to developing countries [16] [17], including in Cameroon, where information about the epidemiology and diversity of dominant risk factors of breast cancer in female populations is often scarce [8] [18].

Few women in Cameroonian cities attend national screening programs when available, partly due to the lack of awareness about breast awareness and screening methods [19] [20]. Unfortunately, mammography is still inaccessible to the majority of the population due to high costs. Thus, cases with breast lumps are detected most often accidentally and more than $80 \%$ of cases are diagnosed in late stages (stages III and IV) where the disease usually has a poor prognosis [7] [9], explaining why in most African countries, the breast cancer survival rate of Cameroon is low. Thus, breast cancer screening population should be a priority in this country, particularly in rural areas where healthcare centers are lacking [21] [22] [23], considering that due to environmental differences, breast cancer incidence is expected to be different as compared to cities [24] [25] [26]. The present study was undertaken to assess the awareness of breast cancer warning 
signs and screening methods in the North Region of Cameroon. We hypothesized that poor awareness about breast cancer, its screening methods and signs by the general population are the major drivers of late diagnosis of breast cancer in Cameroonian rural areas.

\section{Materials and Methods}

\subsection{Study Procedures and Ethical Considerations}

From August $1^{\text {st }}$ to December 28 2019, a cross-sectional and descriptive study was conducted in six health facilities of the North Region of Cameroon. Participants were recruited in the health facilities using simple random sampling. After being presented individually with the study rationale and detailed information on procedures, each participant willing to join the study had to sign an informed consent form. Afterward, she was submitted to a questionnaire that aimed to assess awareness about breast cancer and screening practice, breast cancer risk factors, and to collect some sociodemographic data. Then, a physical breast examination was performed. Women previously diagnosed with breast cancer and women undergoing unilateral or bilateral mastectomy were not included.

Our study participants were 475 women randomly selected among the residents of the rural areas around the city of Garoua, North region, Cameroon. Signed informed consent was obtained from each participant at recruitment. Before analysis, the data collected were anonymized to protect the privacy of participants. All the procedures of the study were approved by the North Regional Delegation of the Ministry of Health (Ref. No. 01832NS/D/DRSP/N/SAG).

\subsection{Data Collection}

Awareness about breast cancer amongst Health professionals was assessed using a questionnaire included questions aimed at assessing the awareness about the recommended screening methods for early detection of breast cancer and knowledge about commonly reported breast cancer symptoms. Amongst the general population, the questionnaire aimed at assessing awareness on breast cancer, its screening methods and practice. Also, it was used to collect some sociodemographic data such as age and educational level of participants.

\subsection{Breast Physical Examination}

During physical breast examination performed in the gynecology service of the health facility, Fine Needle Aspiration (FNA) was performed with the consent of the participant, using recommended standard clinical procedures, when a nodule was identified as well as its characteristics (site, number, consistency, size, mobility relative to deep skin and plans, painful or not). Each sample collected was mounted on a slide, processed for May-Grünwald Giemsa staining, and analyzed using bright-field microscopy (magnifications $4 \mathrm{x}$ to $40 \mathrm{x}$ ) at the Laboratory of Anatomo-Cytopathology of the University Hospital Center of Yaoundé. In case of cancer, Fisher's simplification of Black's nuclear grading scheme was 
used to determine the grade.

Instead, when nipple discharge occurred during the examination, characteristics were determined and recorded as well (aspect, uni- or bilateral, uni- or multi-orifice). Moreover, palpation of armpits was also performed to assess eventual axillary lymph node inflammation. The following characteristics of inflamed axillary lymph nodes were determined and recorded: number, size, and mobility relative to surrounding tissue.

\subsection{Statistical Analysis}

Data was collected, organized, and presented as frequency distributions. Data analysis was performed using XLStat Version 2019. The $\chi^{2}$ test was used to compare proportions and correlations were determined between age, education, occupation, and breast cancer awareness and also with screening practice. Statistical significance was set at $\mathrm{p}<0.05$.

\section{Results}

Out of 475 women interviewed in this study, 37 were health professionals and 438 were general population.

\subsection{Sociodemographic Information}

The Age range was 13 to 72 years old and the median was 42.5. Most participants were younger than $35(84.6 \%)$, had attended at least secondary school (56.6\%), and were not housewives (63.2\%) (Table 1).

\subsection{Awareness of Breast Cancer Risk Factors and Warning Signs}

91.3\% of participants had heard about breast cancer and their main sources of information were their entourage (64.8\%), media (46.5\%), and health professionals (42.7\%) (Table 2). More than $50 \%$ of the population was not aware of breast cancer risk factors. Most of them had misconceptions and myth-based

Table 1. Sociodemographic characteristics of participants.

\begin{tabular}{ccc}
\hline Variables & & $\mathrm{N}(\%)$ \\
\hline Age (years) & $<35$ & $403(84.6)$ \\
& No formal & $72(15.1)$ \\
\hline Education & Primary school & $95(20.0)$ \\
& Secondary school & $111(23.3)$ \\
& University & $221(46.5)$ \\
& Housewife & $48(10.1)$ \\
\hline Occupation & Student & $175(36.8)$ \\
& Officer & $118(24.8)$ \\
& Health professional & $24(5.0)$ \\
& Other, informal sector & $37(7.7)$ \\
\hline
\end{tabular}


Table 2. Breast cancer awareness, and known risk factors and symptoms reported.

\begin{tabular}{|c|c|c|}
\hline Variables & & $\mathrm{N}(\%)$ \\
\hline \multirow[t]{2}{*}{ Awareness } & Heard about breast cancer & $434(91.3)$ \\
\hline & Media & $221(46.5)$ \\
\hline \multirow{8}{*}{ Information sour } & Friends & $308(64.8)$ \\
\hline & Health professionals & $203(42.7)$ \\
\hline & School & $71(15.7)$ \\
\hline & None & $233(49.0)$ \\
\hline & Hereditary & $61(12.8)$ \\
\hline & Prolonged use of pills & $29(6.1)$ \\
\hline & Alcohol and tobacco & $59(12.4)$ \\
\hline & Age & $13(2.7)$ \\
\hline \multirow[t]{9}{*}{ Risk factors } & Obesity & $9(1.8)$ \\
\hline & Prolonged exposure to sun & $16(3.3)$ \\
\hline & Low breastfeeding & $23(4.8)$ \\
\hline & Low deliveries & $7(1.4)$ \\
\hline & Traditional breast massage & $48(10.1)$ \\
\hline & Extended wearing of tight bra & $63(13.2)$ \\
\hline & None & $170(35.7)$ \\
\hline & Lump in the breast & $208(43.7)$ \\
\hline & Pain in the breast & $172(36.2)$ \\
\hline Symptoms & Wound on the breast & $116(24.4)$ \\
\hline & Changes in breast shape and appearance & $108(22.7)$ \\
\hline & Nipple discharge & $61(12.8)$ \\
\hline
\end{tabular}

ideas such as traditional breast massage $(10.1 \%)$ and extended wearing of bra (13.2\%) as the origin of the disease (Table 2). Hereditary factors (12.8\%), and consumption of alcohol and tobacco (12.4\%) were the most known actual risk factors of breast cancer (Table 2). Breast lumps (43.7\%), pain (36.2\%), and wounds (24.4\%) were the most known breast cancer symptoms (Table 2).

\subsection{Awareness of Breast Cancer Screening}

$56.8 \%$ of participants were aware of breast cancer screening and named clinical examination of the breast (34.9\%), BSE (27.7\%) and mammography (21.2\%) as screening tools (Table 3 ). However, only $4.6 \%$ already performed mammography and $24.0 \%$ practiced BSE, of which $31.5 \%$ (7.5\% of the overall participants) do so regularly (Table 3 ). 
Table 3. Breast cancer screening methods cited and personal screening frequency.

\begin{tabular}{ccc}
\hline Variables & $\mathrm{N}(\%)$ \\
\hline Awareness & Neard about screening & $270(56.8)$ \\
\hline Screening methods & Clinical Examination & $32(6.7)$ \\
& BSE ${ }^{\mathrm{a}}$ & $166(34.9)$ \\
& Mammography & $132(27.7)$ \\
& Ultrasound & $89(18.7)$ \\
\hline Screening practice & Mammography & $22(4.6)$ \\
& BSE & $115(24.2)$ \\
\hline BSE practice frequency & Never & $30(6.3)$ \\
& Sometimes & $79(16.6)$ \\
& Often & $36(7.5)$ \\
\hline
\end{tabular}

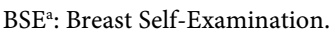

\subsection{Factors Affecting Breast Cancer Awareness and Screening Practice Frequency}

Highly educated women were more likely to identify breast cancer actual risk factors (Table 4). However, they also had misconceptions and myth-based ideas: of the 48 women who attended university, 14 (29.1\%) and 13 (27.0\%, respectively, mentioned traditional breast massage and extended wearing of tight bra as risk factors and 15 (31.2\%) had no idea (Table 4). Similarly, employed women were more aware of the disease, its risk factors and symptoms as compared to other groups $(\mathrm{p}<0.0001)$ for most of the risk factors and symptoms (Table 4$)$. Health professionals displayed better knowledge about breast cancer, although a few also had erroneous ideas and misconceptions (Table 4). Participants with higher education and employed women were also more aware of breast cancer screening, including BSE, mammography, and ultrasound ( $\mathrm{p}<0.0001$ vs. other groups) (Table 4).

Breast Self-Examination practice among the study participants are presented in Table 5. Breast cancer screening and BSE were mostly performed by women with higher education and employed women ( $p<0.0001$ vs. other groups) (Table 5).

\subsection{Breast Examination Findings}

Out of 475 participants, 329 agreed to undergo breast clinical examination as part of breast cancer screening. The following cases were detected: 23 with lumps, 3 with inflamed axillary lymph nodes, 2 with wounds on the breast, and 2 with wounds on the nipple (Table 6). Analyses of fine-needle aspirates of no- 
dules and lesions revealed 5 cases with the following cytological findings: a benign breast tumor, a galactophoric cyst, a cystic abscess, an abscess markedly swollen, and low chronic inflammation.

Table 4. Associations between occupation, education, and breast cancer awareness.

\begin{tabular}{|c|c|c|c|c|c|c|c|c|c|c|c|c|c|}
\hline \multirow[t]{2}{*}{ Variables } & \multirow[b]{2}{*}{$\mathrm{A} 1$} & \multicolumn{3}{|c|}{ Occupation (n) } & \multirow[b]{2}{*}{ A5 } & \multirow[t]{2}{*}{ Total } & \multirow[t]{2}{*}{$\mathbf{P}$} & \multicolumn{4}{|c|}{ Education (n) } & \multirow[t]{2}{*}{ Total } & \multirow[t]{2}{*}{$\mathbf{P}$} \\
\hline & & A2 & A3 & A4 & & & & B1 & B2 & B3 & B4 & & \\
\hline \multicolumn{14}{|c|}{ Risk factors $\left(\mathrm{df}=437, \chi^{2}=91\right)$} \\
\hline None & 110 & 52 & 7 & 4 & 60 & 233 & $0.0001^{\star * *}$ & 61 & 61 & 96 & 15 & 233 & $0.0002^{\star * *}$ \\
\hline Hereditary & 5 & 20 & 7 & 21 & 8 & 61 & $0.0001^{\star * \star}$ & 1 & 4 & 40 & 16 & 61 & $0.0001^{\star * *}$ \\
\hline Use of pills & 2 & 9 & 4 & 10 & 4 & 29 & $0.0001^{\star * *}$ & 0 & 2 & 18 & 9 & 29 & $0.0001^{\star * *}$ \\
\hline Alcohol/tobacco & 7 & 28 & 1 & 16 & 7 & 59 & $0.0001^{\star \star \star}$ & 0 & 4 & 43 & 12 & 59 & $0.0001^{\star * *}$ \\
\hline Age & 2 & 2 & 2 & 5 & 2 & 13 & $0.0002^{\star * *}$ & 0 & 2 & 8 & 3 & 13 & 0.116 \\
\hline Obesity & 2 & 1 & 1 & 5 & 0 & 9 & $0.0001^{\star * \star}$ & 0 & 2 & 4 & 3 & 9 & 0.080 \\
\hline Sun exposure & 3 & 5 & 1 & 4 & 3 & 16 & 0.079 & 0 & 1 & 12 & 3 & 16 & $0.023^{*}$ \\
\hline Breastfeeding & 4 & 6 & 1 & 10 & 2 & 23 & $0.0001^{\star \star \star}$ & 0 & 1 & 17 & 5 & 23 & $0.001^{* *}$ \\
\hline Parity & 2 & 2 & 0 & 2 & 1 & 7 & 0.306 & 0 & 1 & 5 & 1 & 7 & 0.433 \\
\hline Breast massage & 4 & 23 & 4 & 13 & 4 & 48 & $0.0001^{* * *}$ & 0 & 3 & 31 & 14 & 48 & $0.0001^{\star * *}$ \\
\hline Tight bra-wearing & 4 & 29 & 8 & 13 & 9 & 63 & $0.0001^{\star * *}$ & 0 & 4 & 46 & 13 & 63 & $0.0001^{\star * \star}$ \\
\hline \multicolumn{14}{|c|}{ Symptoms $\left(\mathrm{df}=437, \chi^{2}=91\right)$} \\
\hline None & 87 & 19 & 1 & 1 & 62 & 170 & $0.0001^{\star * *}$ & 53 & 65 & 52 & 0 & 170 & $0.0001^{\star * \star}$ \\
\hline Breast lump & 40 & 77 & 22 & 34 & 35 & 208 & $0.0001^{* * *}$ & 9 & 22 & 134 & 43 & 208 & $0.0001^{\star * *}$ \\
\hline Breast pain & 52 & 60 & 14 & 23 & 23 & 172 & $0.0001^{* * *}$ & 15 & 29 & 100 & 28 & 172 & $0.0001^{\star * *}$ \\
\hline Breast wound & 42 & 22 & 7 & 13 & 32 & 116 & 0.289 & 20 & 28 & 53 & 15 & 116 & 0.602 \\
\hline Br. Appearance & 27 & 32 & 10 & 16 & 23 & 108 & $0.0002^{\star * *}$ & 7 & 16 & 68 & 17 & 108 & $0.0001^{\star * *}$ \\
\hline Nipple discharge & 9 & 25 & 6 & 9 & 12 & 61 & $0.0001^{\star * *}$ & 3 & 7 & 42 & 9 & 61 & $0.0001^{\star * *}$ \\
\hline Screening awareness & 77 & 81 & 22 & 37 & 33 & 270 & $\begin{aligned} \mathrm{df} & =12 ; \chi^{2}=74 \\
\mathrm{p} & <0.0001^{\star * *}\end{aligned}$ & 25 & 47 & 154 & 44 & 270 & $\begin{array}{l}\mathrm{df}=9 ; \chi^{2}=91 \\
\mathrm{p}<0.0001^{* * *}\end{array}$ \\
\hline \multicolumn{14}{|c|}{ Screening methods $\left(\mathrm{df}=8 ; \chi^{2}=51.0\right.$ and $\left.\mathrm{df}=6 ; \chi^{2}=97.7\right)$} \\
\hline $\mathrm{BSE}^{\mathrm{a}}$ & 24 & 38 & 17 & 33 & 20 & 132 & $0.0001^{\star * *}$ & 6 & 15 & 74 & 37 & 132 & $0.0001^{\star * \star}$ \\
\hline $\mathrm{CBE}^{\mathrm{b}}$ & 65 & 31 & 8 & 22 & 40 & 166 & $0.028^{*}$ & 22 & 39 & 83 & 22 & 166 & $0.056^{*}$ \\
\hline Mammography & 16 & 33 & 11 & 25 & 16 & 101 & $0.0001^{\star * *}$ & 4 & 13 & 56 & 28 & 101 & $0.0001^{\star * *}$ \\
\hline Ultrasound & 17 & 33 & 11 & 16 & 12 & 89 & $0.0001^{* * *}$ & 4 & 11 & 54 & 20 & 89 & $0.0001^{* * *}$ \\
\hline
\end{tabular}
formal sector; B1 = No formal education; B2 = Primary school; B3 = Secondary school; B4 = University; $\chi^{2}:^{*}=\mathrm{p}<0.05 ;{ }^{* *}=\mathrm{p}<0.005 ;{ }^{* *} \leq 0.0001$. 
Table 5. Factors affecting BSE practice.

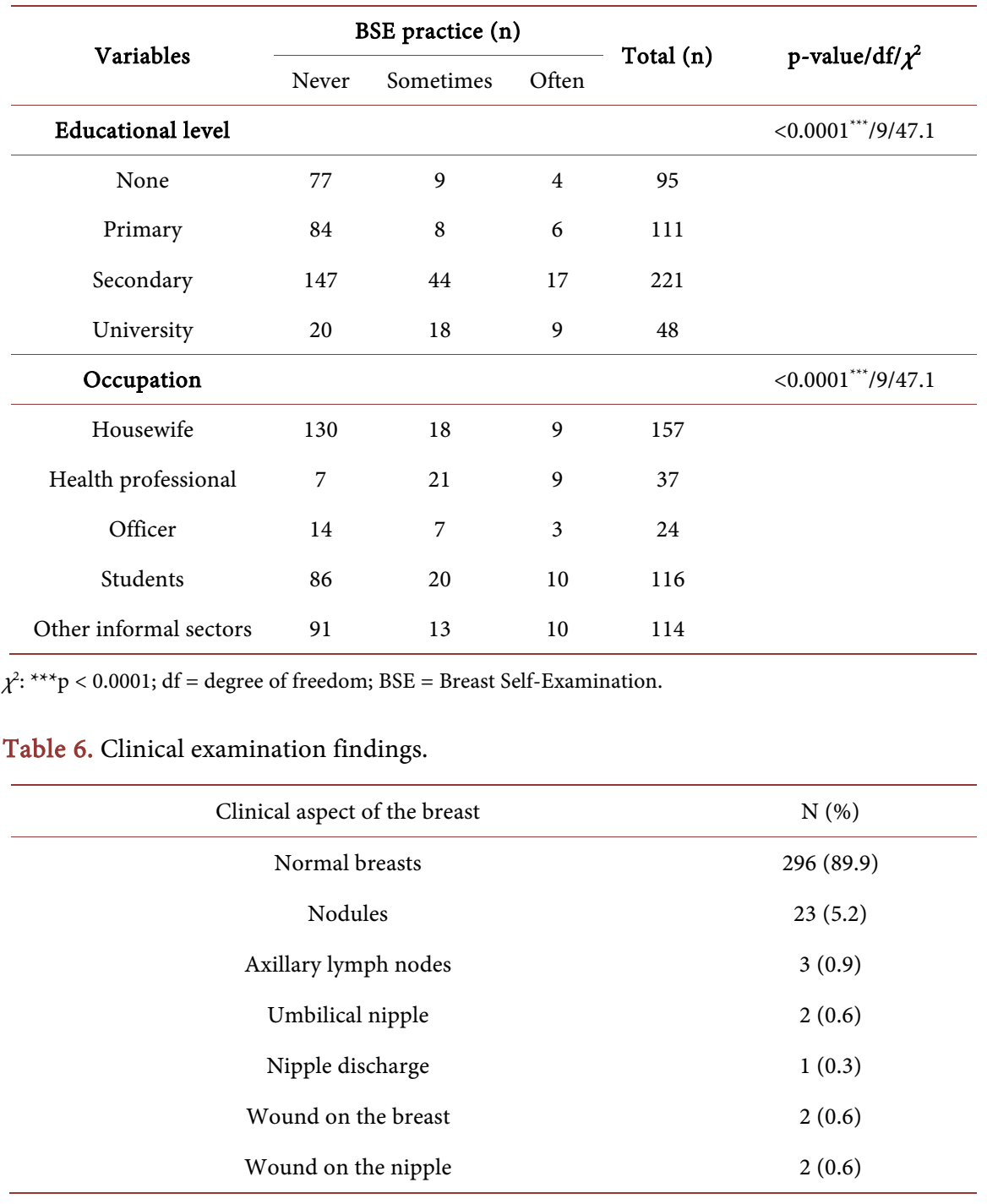

\subsection{Reasons for Not Practicing Screening}

Participants mainly claimed: 1) that should it be breast cancer it could only result from witchcraft and thus, they would not need hospitals to deal with it; 2) a lack of awareness about breast cancer screening methods and fear of discovering that they are sick; 3) to lack time for screening; and 4) that they don't have any complaint and no history of breast cancer in their family, so there is no need for any exam. Other astonishing reasons proposed to reject screening included: 1) This lump in my breast has always been there and never had a problem or any complaint with it, so there is no need for a test; 2) "Breast cancer results from keeping coins in bra and I never do so"; 3) "I do not want to know whether my lump is or is not cancer, because it could result in stress, and I will be rejected by my husband if my breast is removed"; 4) "I don't know how to perform BSE, nobody ever taught me"; and 5) "No one in my family ever had breast cancer and I never had any complaint, that's why I will not perform any screening". 


\section{Discussion}

The results showed that most of the surveyed professionals had good awareness about the existence of breast cancer, but insufficient knowledge and misperceptions on its risk factors and causes, and screening methods as well as infrequent practices of it. More than $50 \%$ of the population was not informed about breast cancer risk factors. Most of them had misconceptions about traditional breast massage (10.1\%) and took extended wearing of bra (13.2\%) as risk factors. These results are surprising, given that most of the study participants had heard about breast cancer (91.6\%) were young, and had the right education level to access more information (46.5\% attended at least secondary school). This could be explained by the fact that many of them heard about the disease from those around them such as friends and family members (64.8\%). Indeed, in traditional African public beliefs, breast cancer is a mystical disease due to supernatural causes, including witchcraft, curses, and divine punishment [12] [23] [27].

Breast pain (34.0\%) and skin ulceration on the breast (23.5\%), presence of a lump in the breast (43.7\%), were the clinical signs most known by women as reported in previous studies [7] [28]. Indeed, in the North region of Cameroon, due to poverty, patients generally consult when breast ulceration is marked or breast lumps are painful, events that usually occur when the disease is already at late stages [10] [11] [12] [13], contributing to late detection of the disease and poor prognosis [7] [9].

Highly educated and employed women in the present study, identified breast cancer risk factors more accurately than uneducated and unemployed women ( $\mathrm{p}$ $<0.0001$ ). However, misconceptions on the origin of the disease were also found here. In the 48 women with university degrees, 14 (29.1\%) and $13(27.0 \%)$ respectively mentioned traditional breast massage and extended wearing of tight bra as risk factors, and 15 (31.2\%) had no idea about disease risk factors. These women confessed their erroneous information came from their entourage, and they did not see the importance of verifying it before participating in the study. This further suggests a lack of public awareness about breast cancer and underlines the need for education for early diagnosis and a better prognosis of the disease. Media could help to disseminate the right information, as they were a source of information for $46.5 \%$ of the participants. Health facilities could help as well, as $28.7 \%$ of the participants reported health education sessions in local languages held during prenatal consultations and immunization days in Cameroonian healthcare centers as their major source of medical information. Studies in comparable contexts showed that presentations in local languages by qualified health professionals attract more auditors [27] [29]. As expected, in this study most health professionals interviewed (and all those working with breast cancer patients) were aware of breast cancer risk factors and listed the clinical signs of the disease accurately. However, only $24.32 \%$ practiced BSE regularly and $10.81 \%$ had already undergone mammography screening as a medical prescription, and none had ever undergone mammography as routine screening. This observation corroborates reports in other African countries [29] [30] and sug- 
gests that good knowledge does not imply better screening practices. This was explained by negligence or the high costs of mammography.

Several other participants reported that it is possible to detect breast cancer early and cite clinical breast examination (32.87\%), BSE (22.60\%), and mammography as screening tools. However, a low level of practice of mammography screening (4.11\%) and BSE (6.16\%) was also observed here, also due to the high cost of mammography, together with a lack of mastery of the BSE technique and the fear of actually discovering a disease sign, considered a harbinger of mastectomy and death [12] [19] [27]. Considering the alarming rates of disease also reported elsewhere in the country, the Cameroonian Government should make mammography, the current gold standard for breast cancer screening, available for free to rural populations, for instance, through screening campaigns. BSE, a low-cost screening option that proved to be effective in similar contexts [1] [31] could be thought and recommended to women during these campaigns as done in various successful breast cancer screening programs worldwide [14] [17] [22] [32].

79 (16.63\%) participants refused clinical examination in this study, as they feared discovering breast cancer or to show their breasts to the medical professionals performing the examinations due to religious reasons (to preserve their intimacy). This also justified the refusal of several participants to be sampled for cytopathological examination of the nodules, as they argued that they needed the consent of their husbands. Breast palpation coupled with fine-needle aspiration, a cost-effective cytopathological analytic technique efficient in this context [33], revealed nodules in $4.55 \%$ of participants [34], confirming the need for breast cancer screening campaigns in Cameroonian rural areas like the North Region.

There is a need to raise awareness among the public about the risk factors and clinical signs of breast cancer and the importance of screening practice by both mammography and regular practice of BSE and CBE in the diagnosis of breast cancer at early stage and management of the disease. The Cameroonian health authorities should organize campaigns for early detection of asymptomatic cases of breast cancer, considering the positive implications for treatment outcomes.

\section{Acknowledgements}

The authors thank the authorities and the health professionals of Garoua Regional Hospital and surrounding health facilities for their help in data collection and all the participants.

\section{Conflicts of Interest}

The authors declare no conflicts of interest regarding the publication of this paper.

\section{References}

[1] Ferlay, J., Colombet, M., Soerjomataram, I., Mathers, C., Parkin, D.M., Piñeros, M., 
Znaor, A. and Bray, F. (2019) Estimating the Global Cancer Incidence and Mortality in 2018: GLOBOCAN Sources and Methods. International Journal of Cancer, 144, 1941-1953. https://doi.org/10.1002/ijc.31937

[2] Matsuda, T. and Okuyama, A. (2018) Cancer Incidence Rates in the World from the Cancer Incidence in Five Continents XI. Japanese Journal of Clinical Oncology, 48, 202-203. https://doi.org/10.1093/jico/hyy007

[3] Youlden, D.R., Cramb, S.M., Yip, C.H. and Baade, P.D. (2014) Incidence and Mortality of Female Breast Cancer in the Asia-Pacific Region. Cancer Biology \& Medicine, 11, 101-115.

[4] Ferlay, J., Soerjomataram, I., Dikshit, R., Eser, S., Mathers, C., Rebelo, M., Parkin, D.M., Forman, D. and Bray, F. (2015) Cancer Incidence and Mortality Worldwide: Sources, Methods and Major Patterns in GLOBOCAN 2012. International Journal of Cancer, 136, E359-E386. https://doi.org/10.1002/ijc.29210

[5] Greenhalgh, J., Bagust, A., Boland, A., Oyee, J., Trevor, N., Beale, S., Dundar, Y., Hockenhull, J., Proudlove, C. and O'Reilly, S. (2015) Eribulin for the Treatment of Advanced or Metastatic Breast Cancer: A NICE Single Technology Appraisal. Pharmacoeconomics, 33, 137-148. https://doi.org/10.1007/s40273-014-0214-2

[6] Bray, F., Ferlay, J., Soerjomataram, I., Siegel, R. L., Torre, L.A. and Jemal, A. (2018) Global Cancer Statistics 2018: GLOBOCAN Estimates of Incidence and Mortality Worldwide for 36 Cancers in 185 Countries. CA: A Cancer Journal for Clinicians, 68, 394-424. https://doi.org/10.3322/caac. 21492

[7] Sama, C.-B., Dzekem, B., Kehbila, J., Ekabe, C.J., Vofo, B., Abua, N.L., Dingana, T.N. and Angwafo, F. (2017) Awareness of Breast Cancer and Breast Self-Examination among Female Undergraduate Students in a Higher Teachers Training College in Cameroon. The Pan African Medical Journal, 28, 91.

https://doi.org/10.11604/pamj.2017.28.91.10986

[8] Adedokun, B., Zheng, Y., Ndom, P., Gakwaya, A., Makumbi, T., Zhou, A.Y., Yoshimatsu, T.F., Rodriguez, A., Madduri, R.K., Foster, I.T., Sallam, A., Olopade, O.I. and Huo, D. (2020) Prevalence of Inherited Mutations in Breast Cancer Predisposition Genes among Women in Uganda and Cameroon. Cancer Epidemiology, Biomarkers \& Prevention, 29, 359-367. https://doi.org/10.1158/1055-9965.EPI-19-0506

[9] Azemfac, K., Christie, S.A., Carvalho, M.M., Nana, T., Fonje, A.N., Halle-Ekane, G., Dicker, R., Chichom-Mefire, A. and Juillard, C. (2019) A Community-Based Assessment of Knowledge and Practice of Breast Self-Examination and Prevalence of Breast Disease in Southwest Cameroon. Journal of Cancer Epidemiology, 2019, Article ID: 2928901. https://doi.org/10.1155/2019/2928901

[10] Okobia, M.N., Bunker, C.H., Okonofua, F.E. and Osime, U. (2006) Knowledge, Attitude and Practice of Nigerian Women towards Breast Cancer: A Cross-Sectional Study. World Journal of Surgical Oncology, 4, 11.

https://doi.org/10.1186/1477-7819-4-11

[11] Orock, G.E., et al. (2012) Current Cancer Incidence and Trends in Yaounde, Cameroon. OGH Reports, 1, 58-63. https://doi.org/10.5530/ogh.2012.1.14

[12] Opoku, S.Y., Benwell, M. and Yarney, J. (2012) Knowledge, Attitudes, Beliefs, Behaviour and Breast Cancer Screening Practices in Ghana, West Africa. The Pan African Medical Journal, 11, 28.

[13] Essiben, F., Foumane, P., Mboudou, E.T., Dohbit, J.S., Koh, V.M. and Ndom, P. (2013) Diagnosis and Treatment of Breast Cancer in Cameroon: A Series of 65 Cases. Le Mali Médical, 28, 1-5.

[14] Zielonke, N., Gini, A., Jansen, E.E.L., Anttila, A., Segnan, N., Ponti, A., Veerus, P., 
de Koning, H.J., van Ravesteyn, N.T., Heijnsdijk, E.A.M., Veerus, P., Anttila, A., Heinävaara, S., Sarkeala, T., Cañada, M., Pitter, J., Széles, G., Voko, Z., Minozzi, S., Segnan, N., Senore, C., van Ballegooijen, M., Driesprong-de Kok, I., Gini, A., Heijnsdijk, E., Jansen, E., de Koning, H., Lansdorp-Vogelaar, I., van Ravesteyn, N., Zielonke, N., Ivanus, U., Jarm, K., Mlakar, D.N., Primic-Žakelj, M., McKee, M. and Priaulx, J. (2020) Evidence for Reducing Cancer-Specific Mortality Due to Screening for Breast Cancer in Europe: A Systematic Review. European Journal of Cancer, 127, 191-206. https://doi.org/10.1016/j.ejca.2019.12.010

[15] Haas, C.B., Nekhlyudov, L., Lee, J.M., Javid, S.H., Bush, M., Johnson, D., Gleason, T., Kaufman, C., Specht, J., Stitham, S. and Wernli, K.J. (2020) Surveillance for Second Breast Cancer Events in Women with a Personal History of Breast Cancer Using Breast MRI: A Systematic Review and Meta-Analysis. Breast Cancer Research and Treatment, 181, 255-268. https://doi.org/10.1007/s10549-020-05637-y

[16] Solikhah, S. and Nurdjannah, S. (2020) Assessment of the Risk of Developing Breast Cancer Using the Gail Model in Asian Females: A Systematic Review. Heliyon, 6, e03794. https://doi.org/10.1016/j.heliyon.2020.e03794

[17] M, S., Dsm, C., et al. (2020) Systematic Review and Meta-Analysis of the 2007 WCRF/AICR Score in Relation to Cancer-Related Health Outcomes. Annals of Oncology, 31, 352-368. https://doi.org/10.1016/j.annonc.2020.01.001

[18] Lukong, K.E., Ogunbolude, Y. and Kamdem, J.P. (2017) Breast Cancer in Africa: Prevalence, Treatment Options, Herbal Medicines, and Socioeconomic Determinants. Breast Cancer Research and Treatment, 166, 351-365. https://doi.org/10.1007/s10549-017-4408-0

[19] Suh, M.A.B., Atashili, J., Fuh, E.A. and Eta, V.A. (2012) Breast Self-Examination and Breast Cancer Awareness in Women in Developing Countries: A Survey of Women in Buea, Cameroon. BMC Research Notes, 5, 627. https://doi.org/10.1186/1756-0500-5-627

[20] Nde, F.P., Assob, J.C.N., Kwenti, T.E., Njunda, A.L. and Tainenbe, T.R.G. (2015) Knowledge, Attitude and Practice of Breast Self-Examination among Female Undergraduate Students in the University of Buea. BMC Research Notes, 8, 43. https://doi.org/10.1186/s13104-015-1004-4

[21] Rositch, A.F., Unger-Saldaña, K., DeBoer, R.J., Ng'ang'a, A. and Weiner, B.J. (2020) The Role of Dissemination and Implementation Science in Global Breast Cancer Control Programs: Frameworks, Methods, and Examples. Cancer, 126, 2394-2404. https://doi.org/10.1002/cncr.32877

[22] Insamran, W. and Sangrajrang, S. (2020) National Cancer Control Program of Thailand. Asian Pacific Journal of Cancer Prevention, 21, 577-582. https://doi.org/10.31557/APJCP.2020.21.3.577

[23] Sayed, S., Ngugi, A.K., Mahoney, M.R., Kurji, J., Talib, Z.M., Macfarlane, S.B., Wynn, T.A., Saleh, M., Lakhani, A., Nderitu, E., Agoi, F., Premji, Z., Zujewski, J.A. and Moloo, Z. (2019) Breast Cancer Knowledge, Perceptions and Practices in a Rural Community in Coastal Kenya. BMC Public Health, 19, 180.

https://doi.org/10.1186/s12889-019-6464-3

[24] Natarajan, R., Aljaber, D., Au, D., Thai, C., Sanchez, A., Nunez, A., Resto, C., Chavez, T., Jankowska, M.M., Benmarhnia, T., Yang, J.-A., Jones, V., Tomsic, J., McCune, J.S., Sistrunk, C., Doan, S., Serrano, M., Cardiff, R.D., Dietze, E.C. and Seewaldt, V.L. (2020) Environmental Exposures during Puberty: Window of Breast Cancer Risk and Epigenetic Damage. International Journal of Environmental Research and Public Health, 17, 493. https://doi.org/10.3390/ijerph17020493

[25] Monteiro, A.N., Bouwman, P., Kousholt, A.N., Eccles, D.M., Millot, G.A., Masson, 
J.-Y., Schmidt, M.K., Sharan, S.K., Scully, R., Wiesmüller, L., Couch, F. and Vreeswijk, M.P.G. (2020) Variants of Uncertain Clinical Significance in Hereditary Breast and Ovarian Cancer Genes: Best Practices in Functional Analysis for Clinical Annotation. Journal of Medical Genetics, 57, 509-518.

https://doi.org/10.1136/jmedgenet-2019-106368

[26] Wood, M.E., Rehman, H. and Bedrosian, I. (2020) Importance of Family History and Indications for Genetic Testing. The Breast Journal, 26, 100-104.

https://doi.org/10.1111/tbj.13722

[27] Kudzawu, E., Agbokey, F. and Ahorlu, C. (2016) A Cross Sectional Study of the Knowledge and Practice of Self-Breast Examination among Market Women at the Makola Shopping Mall, Accra, Ghana. Advances in Breast Cancer Research, 5, 111-120. https://doi.org/10.4236/abcr.2016.53013

[28] Dahiya, N., Basu, S., Singh, M.C., Garg, S., Kumar, R. and Kohli, C. (2018) Knowledge and Practices Related to Screening for Breast Cancer among Women in Delhi, India. Asian Pacific Journal of Cancer Prevention, 19, 155-159.

[29] Bello, T.O., Olugbenga-Bello, A.I., Oguntola, A.S., Adeoti, M.L. and Ojemakinde, O.M. (2011) Knowledge and Practice of Breast Cancer Screening among Female Nurses and Lay Women in Osogbo, Nigeria. West African Journal of Medicine, 30, 296-300.

[30] Nguefack, C.T., N'djeudjui, C., Engbang, J.P.N., Nana, T.N., Ekane, G.H. and Tebeu, P.-M. (2018) Knowledge, Attitude, and Practice on Breast Cancer among Health Professionals in Douala References Hospitals, Cameroon. Journal of Cancer Education, 33, 457-462. https://doi.org/10.1007/s13187-016-1158-3

[31] Lauby-Secretan, B., et al. (2015) Breast-Cancer Screening-Viewpoint of the IARC Working Group. The New England Journal of Medicine, 372, 2353-2358. https://doi.org/10.1056/NEJMsr1504363

[32] Charaka, H., Khalis, M., Elfakir, S., Khazraji, Y.C., Zidouh, A., Abousselham. L., Rhazi, K.E., Lyoussi, B. and Nejjari, C. (2017) Organization and Evaluation of Performance Indicators of a Breast Cancer Screening Program in Meknes-Tafilalt Region, Morocco. Asian Pacific Journal of Cancer Prevention, 17, 5153-5157.

[33] Abuidris, D.O., Elsheikh, A., Ali, M., Musa, H., Elgaili, E., Ahmed, A.O., Sulieman, I. and Mohammed, S.I. (2013) Breast-Cancer Screening with Trained Volunteers in a Rural Area of Sudan: A Pilot Study. The Lancet Oncology, 14, 363-370. https://doi.org/10.1016/S1470-2045(12)70583-1

[34] Richard, T.S., Ndopwang, L.C.C., Seke Etet, P.F., Nwabo Kamdje, A.H., Mohamadou, H., Phelix Bruno, T. and Nangue, C. (2020) Breast Cancer Awareness and Detection of Asymptomatic Cases Using Breast Palpation and Fine-Needle Aspiration in Bafoussam, Cameroon. The Asian Pacific Journal of Cancer Care, 5, 61-66. https://doi.org/10.31557/apjcc.2020.5.1.61-66 